This paper was published in IEEE Transactions on Industrial Electronics in 2014, doi 10.1109/TIE.2014.2385043, and is available at:

http://ieexplore.ieee.org/stamp/stamp.jsp?tp=\&arnumber=6994769

D. Wu, R. Todd, A.J. Forsyth, "Adaptive Rate-Limit Control for Energy Storage Systems," IEEE Transactions on Industrial Electronics, 2014, doi: 10.1109/TIE.2014.2385043

(C) 2014 IEEE. Personal use of this material is permitted. Permission from IEEE must be obtained for all other uses, in any current or future media, including reprinting/republishing this material for advertising or promotional purposes, creating new collective works, for resale or redistribution to servers or lists, or reuse of any copyrighted component of this work in other works. 


\title{
Adaptive Rate-Limit Control for Energy Storage Systems
}

\author{
D. Wu, R. Todd, Senior Member, IEEE and A.J. Forsyth, Senior Member, IEEE
}

\begin{abstract}
An adaptive energy management control with an integrated variable rate-limit function is described for an energy storage system (ESS). The proposed control protects the primary power source(s) in the system as effectively as possible from sudden load transients within the constraints of the available stored energy. The control can be designed to use the available energy more aggressively during load changes in the low or high power regions while offering the lowest possible rate-of-change of main source power, or offer a fixed minimum rate-of-change in power for a given total load and amount of energy. The control design is described in detail and demonstrated experimentally when applied to a super-capacitor energy storage system within an aircraft test facility.
\end{abstract}

Index Terms - Energy Storage System, Energy Management

\section{NOMENCLATURE}

$\mathrm{C}_{\mathrm{sc}}$

$\mathrm{D}$

$\mathrm{E}$

$\mathrm{E}_{\mathrm{L}}, \mathrm{C}, \mathrm{H}$

$\mathrm{E}_{\mathrm{sc}}$

$\mathrm{E}_{\mathrm{t}}, \mathrm{E}_{\mathrm{t}}{ }^{\prime}$

$\mathrm{I}_{\mathrm{AL}}$

$\mathrm{I}_{\mathrm{ESS}}$

$I_{\text {gen }}$

$\mathrm{I}_{\mathrm{RL}}$

$\mathrm{I}_{\mathrm{p}}$

$\mathrm{I}_{\mathrm{sc}}, \mathrm{I}_{\mathrm{sc}-\mathrm{ref}}$

$\mathrm{k}_{\mathrm{c}}$

$P_{\text {ESS }}$

$\mathrm{P}_{\text {ESS-L }}$

$\mathrm{P}_{\text {ESS-re }}$

$\mathrm{P}_{\text {ESS-ref }}$

$\mathrm{P}_{\mathrm{L}}$

$\mathrm{P}_{\mathrm{Lt}}$

$\mathrm{P}_{\mathrm{S}}$

$\mathrm{P}_{\mathrm{sc}-\mathrm{L}}$

$\mathrm{P}_{\text {sc-re }}$

$\mathrm{P}_{\text {sc-ref }}$

$\mathrm{P}_{\mathrm{S}-\mathrm{L}}, \mathrm{C}, \mathrm{H}$

$\mathrm{V}_{\text {bus }}$

$\mathrm{V}_{\mathrm{sc}}$

$\mathrm{V}_{\text {sc-t }}$

$v_{\text {iref }}$
Super-capacitor capacitance

Duty ratio

ESS energy

ESS energy using profiles L, C and $\mathrm{H}$

Energy stored in super-capacitor

Target and usable target energy

Active load current

ESS current

Generator current

Resistive load current

Peak current in peak current controller

Super-capacitor current and reference

Rate-of-change in $\mathrm{P}_{\mathrm{S}}$

Output power of the ESS

Load component of $\mathrm{P}_{\mathrm{ESS}-\mathrm{ref}}$

Recharge component of $\mathrm{P}_{\text {ESS-ref }}$

ESS power reference

Load power

Intermediate load power

Power source output power

Load component of $\mathrm{P}_{\text {sc-ref }}$

Recharge component of $\mathrm{P}_{\text {sc-ref }}$

Super-capacitor power reference

$\mathrm{P}_{\mathrm{S}}$ using profile $\mathrm{L}, \mathrm{C}$ and $\mathrm{H}$

DC bus voltage

Super-capacitor terminal voltage

Target super-capacitor voltage

Current reference of the peak current controller

\section{INTRODUCTION}

Tn the more-electric aircraft, traditional mechanical, hydraulic and pneumatic systems, which tend to be heavy, bulky and inefficient, are replaced by power electronic converter-based solutions, which are expected to be lighter, smaller and more efficient. Further reductions in mass and complexity may be achieved by replacing multiple types of power distribution systems with a single electrical system which also allows more flexible energy usage [1]. However, the introduction of more electrical equipment not only increases the required capacity of the electrical system, but also creates challenges of managing the energy flows and power quality. This is due to the high peak power requirements of some loads, the rapid load transients that may occur, and the fact that most motor drives and power electronic converters have constant power characteristics [2].

One approach to help solve the problems of energy management, power quality and stability is the use of energy storage systems (ESSs). A variety of control methods have been proposed for ESSs including supplying peak power demands [2], optimising efficiency [3], managing energy storage availability [4], [5], and ensuring power quality [6], [7] and stability of an electric system. Furthermore some efforts have been made to consider multiple objectives, most commonly seen in strategies using fuzzy logic [8] or neural networks [3].

Zhang et al. [9] suggests the use of an ESS in aerospace applications with highly dynamic loads to reduce the rate-of-change of power demanded from the sources, such as fuel-cells and gas-turbine-driven generators. Alleviating the sudden load changes from the sources may reduce losses, prevent excessive wear and extend the lifetime. A direct solution to constrain the rate-of-change in output power or current from the main power source is to use a rate-limiter to command the ESS as in the fuel-cell system [7]. The permissible rate-of-change is a compromise between protecting the power source and increasing the size of the storage system.

Work in [10] - [13] uses low-pass filters (LPFs) to provide a rate-limited demand signal to sensitive power sources with a separate control to regulate the ESS voltage and manage energy usage. A fixed time constant is used in the LPF and so the ESS has the same response for a specific power step across the full load range. Determining the time constant for the LPF is also a challenge, since this affects the level of utilisation of the ESS [14] and the extent of the performance improvement. As an 
alternative to the use of a constant rate-limiter or a low-pass filter, the author of [15] uses a Kalman filter to calculate a dynamic average of the total required power for the main power source to follow.

Existing ESS controllers with rate-limit functions either have a fixed rate, which is likely to provide sub-optimal use of the storage capacity under many conditions, or they can be complex to design for optimal operation. To address these issues, an adaptive energy management control with integrated rate-limit is proposed. The control has the advantage that it shields the primary power source(s) in the system from sudden load transients within the constraints of the available ESS energy. Different control designs enable the most effective use of the available energy during load changes in the low or high power regions while offering the lowest possible rate-of-change of main source power, or offer a fixed minimum rate-of-change in power for a given total load and amount of energy.

This paper is organised as follows:

- General analysis of an ESS is presented in Section II.

- The proposed control is explained in Section III and applied to a general ESS in Section IV.

- An overview of the experimental system, together with validation results is given in Section $\mathrm{V}$.

\section{GENERAL ANALYSIS OF AN ESS}

The proposed energy management control has two functions, managing the available energy in the ESS and regulating the rate-of-change of source power. These two aspects of the ESS behaviour are examined in detail in this section as this analysis forms the theoretical basis for the proposed control.

\section{A. Steady-State}

Fig. 1 shows three profiles of stored energy versus load power, labelled L, C and $\mathrm{H}$.

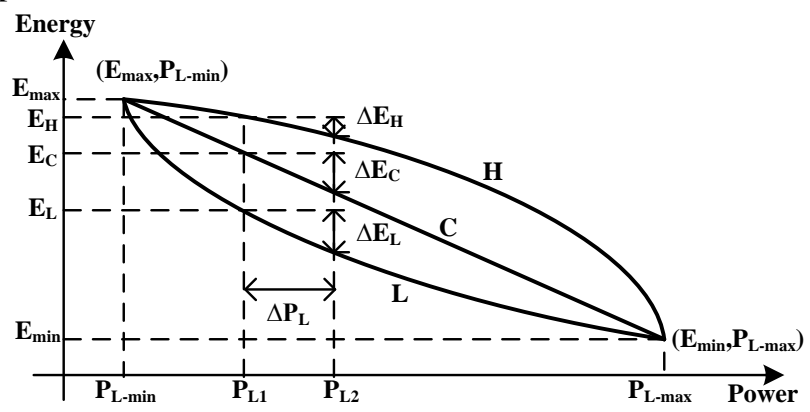

Fig. 1 Sample stored energy against load power profiles.

All of the profiles in Fig. 1 pass the same two points, $E_{\max }$, $\mathrm{P}_{\mathrm{L}-\mathrm{min}}$ where the energy storage unit is full and the load is at its minimum, and $\mathrm{E}_{\min }, \mathrm{P}_{\mathrm{L}-\max }$ where the energy storage unit is at its minimum and the maximum load is applied within the system. In the analysis in this section, the minimum load power $\mathrm{P}_{\mathrm{L}-\min }$ is assumed to be zero.

For a specific load $\mathrm{P}_{\mathrm{L} 1}$ in Fig. 1, each profile has a different steady-state energy with profile $\mathrm{L}$ having the lowest stored energy, $\mathrm{E}_{\mathrm{L}}$, and profile $\mathrm{H}$ having the highest remaining stored energy, $\mathrm{E}_{\mathrm{H}}$, for the profiles examined. In general the stored energy $\mathrm{E}$ may be expressed as a function of load power $\mathrm{P}_{\mathrm{L}}$ :

$$
E=f_{s s}\left(P_{L}\right)
$$

where the function $\mathrm{f}_{\mathrm{ss}}()$ defines the shape of the profile and should be monotonically decreasing so that it satisfies the general ESS rule of high stored energy at low load, and low stored energy at high load. Other alternative profiles are valid providing they pass the two points, $\mathrm{E}_{\max }, \mathrm{P}_{\mathrm{L}-\min }$ and $\mathrm{E}_{\min }, \mathrm{P}_{\mathrm{L}-\max }$ as these define the limits of device and system operation.

The main difference amongst the profiles in Fig. 1 is the different energy flow for a specific load step at different levels of load power, which is reflected in the slope of each profile. Profile L has a high $\mathrm{dE} / \mathrm{dP}$ at low load power and low $\mathrm{dE} / \mathrm{dP}$ at high load power, indicating that at low load powers the storage system will respond more strongly, i.e., the low power region is prioritised; profile $\mathrm{H}$ works in the opposite way and so prioritises the high power region, and profile $\mathrm{C}$ has a constant $\mathrm{dE} / \mathrm{dP}$ and so the storage system will respond in a similar manner at all load levels. As an example, a load step $\Delta \mathrm{P}_{\mathrm{L}}$ from $P_{L 1}$ to $P_{L 2}$ shown in Fig. 1 results in a different change in energy using profiles $\mathrm{L}, \mathrm{C}$ and $\mathrm{H}$. Since the load is in the low power region, profile $\mathrm{L}$ results in more energy being consumed, $\Delta \mathrm{E}_{\mathrm{L}}$, than the other profiles. For a load step in the high power region, profile $\mathrm{H}$ would use more energy in response to the step than either profile C or L. Simple piecewise linear profiles with no rate-limit function have previously demonstrated this concept [16].

\section{B. Dynamic Response}

To examine the shape of the ESS power transients that occur in response to a step change in load, and the resultant transient imposed on the power source, a sample load power step from $\mathrm{P}_{\mathrm{L} 1}$ to $\mathrm{P}_{\mathrm{L} 2}$ is shown in Fig. 2 for a system consisting of a single ESS. The consumed/stored energy $\triangle \mathrm{E}$ from/to the ESS in response to the load change, is the integral of the difference between the load and source powers with time, (2). Taking $\mathrm{P}_{\mathrm{S} 1}$ as an example gives the shaded area in Fig. 2.

$$
\Delta E=\int P_{E S S} d t=\int\left(P_{L}-P_{S}\right) d t
$$

In all cases in Fig. 2a, the ESS responds instantaneously to the change in load (profiles $\mathrm{P}_{\mathrm{ESS} 1}, \mathrm{P}_{\mathrm{ESS} 2}, \mathrm{P}_{\mathrm{ESS} 3}$ ), and the power source has a zero instantaneous response and then gradually the source output $\mathrm{P}_{\mathrm{S} 1}, \mathrm{P}_{\mathrm{S} 2}, \mathrm{P}_{\mathrm{S} 3}$ increases to match the load power. The three profiles all consume the same amount of stored energy $\Delta \mathrm{E}$ to enable a fair comparison. Similar behaviour is shown in Fig. 2b for a load decrease, however, the ESS absorbs power in this case and the source power decreases gradually.

For profile $\mathrm{P}_{\mathrm{S} 1}$ in Fig. 2, the source power has a gentle initial response (low $\mathrm{dP}_{\mathrm{S}} / \mathrm{dt}$ ) but encounters a high rate-of-change in power as $\mathrm{P}_{\mathrm{ESS} 1}$ approaches zero. Profile $\mathrm{P}_{\mathrm{S} 3}$ is the opposite of profile $\mathrm{P}_{\mathrm{S} 1}$, with a high initial $\mathrm{dP}_{\mathrm{S}} / \mathrm{dt}$ and a much reduced $\mathrm{dP}_{\mathrm{S}} / \mathrm{dt}$ as $\mathrm{P}_{\mathrm{ESS} 3}$ approaches zero. Profile $\mathrm{P}_{\mathrm{S} 2}$ has a constant rate-of-change in power and so has the lowest peak $\mathrm{dP}_{\mathrm{S}} / \mathrm{dt}$ when compared to $\mathrm{P}_{\mathrm{S} 1}$ and $\mathrm{P}_{\mathrm{S} 3}$, for the same energy usage, and so is used in the proposed control. 

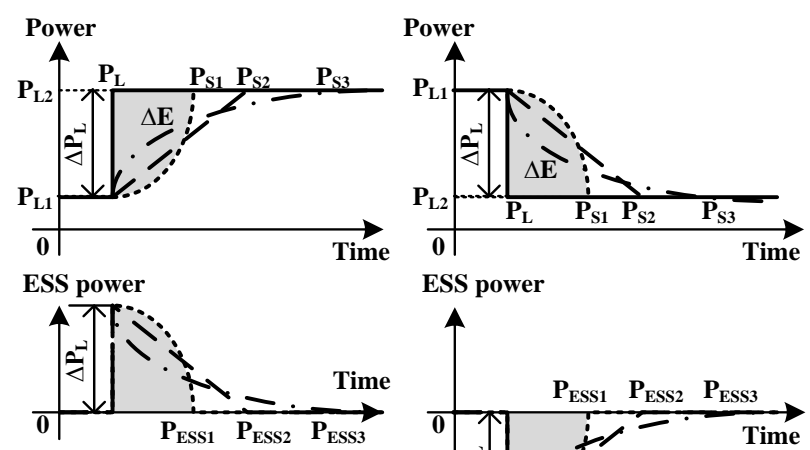

ESS power

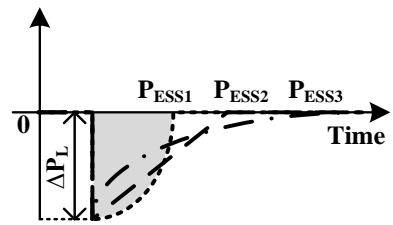

(a) Discharge

(b) Charge.

Fig. 2 Three different power source response profiles.

By using the constant $\mathrm{dP}_{\mathrm{S}} / \mathrm{dt}$ rate profile $\mathrm{P}_{\mathrm{S} 2}$ and denoting $\mathrm{dP}_{\mathrm{S}} / \mathrm{dt}$ equal to $\mathrm{k}_{\mathrm{c}}$, the energy used during the transition of $\mathrm{P}_{\mathrm{L} 1}$ to $\mathrm{P}_{\mathrm{L} 2}\left(\Delta \mathrm{P}_{\mathrm{L}}=\mathrm{P}_{\mathrm{L} 2}-\mathrm{P}_{\mathrm{L} 1}\right)$ in Fig. 2 can be worked out using (2):

$$
\Delta E=\frac{1}{2} \Delta P_{L} \cdot \Delta t=\frac{1}{2} \Delta P_{L} \cdot \frac{\Delta P_{L}}{k_{c}}=\frac{1}{2} \frac{\Delta P_{L}^{2}}{k_{c}}
$$

The rate-of-change in power source output $\mathrm{dP}_{\mathrm{S}} / \mathrm{dt}=\mathrm{k}_{\mathrm{c}}$, can be determined from (3) as:

$$
\frac{d P_{s}}{d t}=k_{c}=\frac{\Delta P_{L}^{2}}{2 \Delta E}
$$

Eq. (4) reflects the simple fact that the dynamic response of the power source, $\mathrm{dP}_{\mathrm{S}} / \mathrm{dt}$ (or $\mathrm{k}_{\mathrm{c}}$ ), will be gentler if exposed to a small load change $\Delta \mathrm{P}_{\mathrm{L}}$ with a large available stored energy $\Delta \mathrm{E}$. The $\mathrm{k}_{\mathrm{c}}$ value also indicates the minimum possible rate-of-change in power throughout the load transition given a known $\Delta \mathrm{P}_{\mathrm{L}}$ and $\Delta \mathrm{E}$, since using any other non-constant $\mathrm{dP}_{\mathrm{S}} / \mathrm{dt}$ profile will result in a larger peak rate-of-change in power as illustrated in Fig. 2.

By considering the extreme case when the load changes from $\mathrm{P}_{\mathrm{L} \text {-min }}$ to $\mathrm{P}_{\mathrm{L}-\max }$ (or vice versa), and all the available energy is used (or stored), i.e., $\Delta \mathrm{E}=\mathrm{E}_{\max }-\mathrm{E}_{\min }, \Delta \mathrm{P}_{\mathrm{L}}=\mathrm{P}_{\mathrm{L}-\max }-\mathrm{P}_{\mathrm{L}-\min }$, the rate-of-change in power for this condition is $\mathrm{k}_{\mathrm{c}-\max }$, which is an upper bound, and can be determined from (4) as:

$$
k_{c-\max }=\frac{\left(P_{L-\max }-P_{L-\min }\right)^{2}}{2\left(E_{\max }-E_{\min }\right)}
$$

Since this $\mathrm{dP}_{\mathrm{S}} / \mathrm{dt}$ rate is fixed for the known total storage capacity $\Delta \mathrm{E}=\mathrm{E}_{\max }-\mathrm{E}_{\min }$ and maximum and minimum load power $\mathrm{P}_{\mathrm{L}-\max }$ and $\mathrm{P}_{\mathrm{L}-\min }$, the control objective is to make sure that the $\mathrm{dP}_{\mathrm{S}} / \mathrm{dt}$ rate for other load steps is equal to or less than $\mathrm{k}_{\mathrm{c}-\max }$ during the resulting charge or discharge process, therefore:

$$
k_{c}=\frac{\Delta P_{L}^{2}}{2 \Delta E} \leq k_{c-\max }=\frac{\left(P_{L-\max }-P_{L-\min }\right)^{2}}{2\left(E_{\max }-E_{\min }\right)}
$$

To achieve this objective, together with the energy usage from Section II.A, a control method is proposed and described in Section III.

\section{Control Design}

The proposed ESS control method shown in Fig. 3 determines the power reference $\mathrm{P}_{\mathrm{ESS} \text {-ref }}$ which commands the ESS to provide/consume the required power, using two separate components given in (7).

$$
P_{E S S-r e f}=P_{E S S-L}-P_{E S S-r e}=P_{L}-P_{E S S-r e}
$$

where the load power balance control component $\mathrm{P}_{\text {ESS-L }}$ is the measured load power $\mathrm{P}_{\mathrm{L}}$, and $\mathrm{P}_{\mathrm{ESS}-\mathrm{re}}$ is the recharge component which manages the ESS energy.

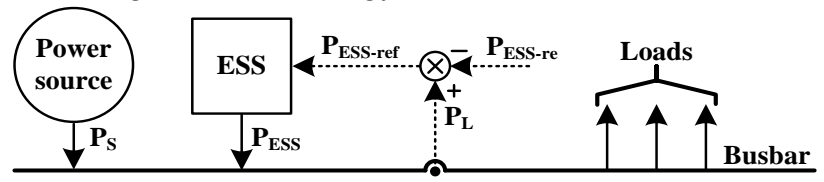

Fig. 3 Generic electrical system with an ESS

Assuming a lossless system, and that the ESS accurately follows the reference value, so $\mathrm{P}_{\mathrm{ESS}}=\mathrm{P}_{\mathrm{ESS}-\text { ref }}$, the ESS output power is given by:

$$
P_{E S S}=P_{E S S-r e f}=P_{L}-P_{S}
$$

From (7) and (8), it can be deduced that:

$$
P_{S}=P_{E S S-r e}
$$

Eq. (9) shows that the power source output $P_{S}$ is indirectly controlled by $\mathrm{P}_{\text {ESS-re. }}$. Therefore the proposed control method is to set $\mathrm{P}_{\mathrm{ESS}-\mathrm{re}} \mathrm{SO}$ as to manage the dynamic power performance of the power source and also the energy level of the ESS. The proposed method is applicable to a generic electrical system with any ESS, and the controller design is given in Section III.A and III.B.

\section{A. State-of-charge control}

The process for managing energy is developed by considering the discharge and charge of the ESS.

A discharge cycle is shown in Fig. 4a, where the load power $\mathrm{P}_{\mathrm{L}}$ (solid line) changes in steps from $\mathrm{P}_{\mathrm{L}-\mathrm{min}}$ to $\mathrm{P}_{\mathrm{Lt}}$ and then to $\mathrm{P}_{\mathrm{L}-\max }$ and the power source output $\mathrm{P}_{\mathrm{S}}$ (dashed line) changes with a fixed rate $k_{c}$ given by (4) which respects the $k_{c-m a x}$ constraint over the full load profile. The energies consumed in response to the two steps are labelled as $\Delta \mathrm{E}_{\mathrm{I}}$ and $\Delta \mathrm{E}_{\mathrm{II}}$ in Fig. 4, and $E_{t}$ is the corresponding total remaining stored energy at load power $\mathrm{P}_{\mathrm{Lt}}$.

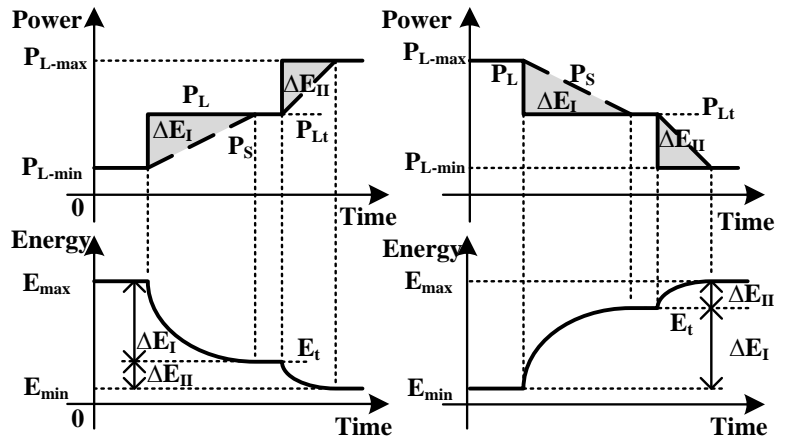

(a) Discharge.

Fig. 4 Full discharge and charge cycle of the ESS.

(b) Charge.

For any intermediate load power level $\mathrm{P}_{\mathrm{L} t}$, sufficient energy $\Delta \mathrm{E}_{\mathrm{II}}=\mathrm{E}_{\mathrm{t}}-\mathrm{E}_{\min }$ has to be reserved to ensure that the ESS is able to respond to a load increase from $\mathrm{P}_{\mathrm{Lt}}$ to the full load power $\mathrm{P}_{\mathrm{L}-\max }$, while restricting $\mathrm{dP}_{\mathrm{S}} / \mathrm{dt}$ to the maximum rate $\mathrm{k}_{\mathrm{c}-\max }$ from (5).

The energy required $\Delta \mathrm{E}=\Delta \mathrm{E}_{\mathrm{II}}=\mathrm{E}_{\mathrm{t}}-\mathrm{E}_{\min }$ at any intermediate load level $\mathrm{P}_{\mathrm{Lt}}$ can be solved by substituting $\Delta \mathrm{E}=\mathrm{E}_{\mathrm{t}}-\mathrm{E}_{\min }$, and $\Delta \mathrm{P}_{\mathrm{L}}=\mathrm{P}_{\mathrm{L}-\max }-\mathrm{P}_{\mathrm{Lt}}$ into (6), so:

$$
k_{c}=\frac{\left(P_{L-\max }-P_{L t}\right)^{2}}{2\left(E_{t}-E_{\min }\right)} \leq k_{c-\max }=\frac{\left(P_{L-\max }-P_{L-\min }\right)^{2}}{2\left(E_{\max }-E_{\min }\right)}
$$


which can be rearranged as:

$$
E_{t} \geq \frac{\left(P_{L-\max }-P_{L t}\right)^{2}}{\left(P_{L-\max }-P_{L-\min }\right)^{2}}\left(E_{\text {max }}-E_{\text {min }}\right)+E_{\text {min }}
$$

Similarly, for a charge process, Fig. $4 \mathrm{~b}$, a sufficient energy margin $\Delta \mathrm{E}=\Delta \mathrm{E}_{\mathrm{II}}=\mathrm{E}_{\max }-\mathrm{E}_{\mathrm{t}}$ has to be reserved for a potential power decrease from the load power $\mathrm{P}_{\mathrm{Lt}}$ to the minimum load power $\mathrm{P}_{\mathrm{L}-\min }$, the solution is to substitute $\Delta \mathrm{E}=\Delta \mathrm{E}_{\mathrm{II}}=\mathrm{E}_{\max }-\mathrm{E}_{\mathrm{t}}$, and $\Delta \mathrm{P}_{\mathrm{L}}=\mathrm{P}_{\mathrm{Lt}}-\mathrm{P}_{\mathrm{L}-\min }$ into (6), which gives:

$$
E_{t} \leq E_{\max }-\frac{\left(P_{L t}-P_{L-\min }\right)^{2}}{\left(P_{L-\max }-P_{L-\min }\right)^{2}}\left(E_{\text {max }}-E_{\text {min }}\right)
$$

Eq. (11) and (12) define two steady-state profiles of energy against load power, i.e., $\mathrm{E}_{\mathrm{t}}=\mathrm{f}_{\mathrm{ss}}\left(\mathrm{P}_{\mathrm{Lt}}\right)$ in the form of (1), so that the target energy $\mathrm{E}_{\mathrm{t}}$ obtained from the profile ensures $\mathrm{k}_{\mathrm{c}} \leq \mathrm{k}_{\mathrm{c}-\max }$ for a discharge process from any load power $\mathrm{P}_{\mathrm{Lt}}$ to maximum load power $\mathrm{P}_{\mathrm{L}-\max }$ or a charge process from any power $\mathrm{P}_{\mathrm{Lt}}$ to minimum power $\mathrm{P}_{\mathrm{L}-\mathrm{min}}$ respectively.

By defining $\mathrm{E}_{\mathrm{t}}{ }^{\prime}=\mathrm{E}_{\mathrm{t}}-\mathrm{E}_{\min }$, and $\mathrm{P}_{\mathrm{L}}{ }^{\prime}=\mathrm{P}_{\mathrm{Lt}}-\mathrm{P}_{\mathrm{L}-\mathrm{min}}$, (11) and (12) can be generalised as:

$$
\begin{array}{lc}
\frac{E_{t}{ }^{\prime}}{E_{\max }-E_{\min }} \geq\left(1-\frac{P_{L}{ }^{\prime}}{P_{L-\max }-P_{L-\min }}\right)^{2} & \text { for discharging } \\
\frac{E_{t}{ }^{\prime}}{E_{\max }-E_{\min }} \leq 1-\left(\frac{P_{L}{ }^{\prime}}{P_{L-\max }-P_{L-\min }}\right)^{2} & \text { for charging }
\end{array}
$$

Eqs. (13) and (14) can be rewritten in per unit terms by defining $\mathrm{E}_{\text {base }}=\mathrm{E}_{\max }-\mathrm{E}_{\min }, \mathrm{P}_{\mathrm{L}-\text { base }}=\mathrm{P}_{\mathrm{L}-\max }-\mathrm{P}_{\mathrm{L}-\min }$, and by setting $\mathrm{E}_{\mathrm{t}-\mathrm{pu}}=\mathrm{E}_{\mathrm{t}}{ }^{\prime} / \mathrm{E}_{\text {base }}, \mathrm{P}_{\mathrm{L}-\mathrm{pu}}=\mathrm{P}_{\mathrm{L}}{ }^{\prime} / \mathrm{P}_{\mathrm{L}-\text { base }}$ :

$$
\begin{array}{lc}
E_{t-p u} \geq\left(1-P_{L-p u}\right)^{2} & \text { for discharging } \\
E_{t-p u} \leq 1-P_{L-p u}{ }^{2} & \text { for charging }
\end{array}
$$

Eq. (15) is the form of profile L in Fig. 1, either reflected from the equation itself or from illustration in Fig. 4a. The state-of-charge at a particular load power is the lowest amongst the three profiles, indicating that more energy will be transferred in response to transients at low load levels, whilst the minimum possible energy is reserved to meet potential load increases up to full power at a $\mathrm{dP}_{\mathrm{S}} / \mathrm{dt}$ rate of $\mathrm{k}_{\mathrm{c}-\max }$. In contrast profile $\mathrm{H}$ (represented by (16)) works in the opposite way and provides the highest state-of-charge at any load level, just reserving enough storage capacity to respond to a load decrease to $\mathrm{P}_{\mathrm{L}-\min }$ at a $\mathrm{dP}_{\mathrm{S}} / \mathrm{dt}$ rate of $\mathrm{k}_{\mathrm{c}-\max }$. The two parabolas of these two equations enclose an area in which the two inequalities, (15) and (16), are always satisfied, and include the linear profile $\mathrm{C}$ in Fig. 1, which is given by:

$$
E_{t-p u}=1-P_{L-p u}
$$

According to the requirements of an application, any one, or a blended combination of these profiles could be used, for example blending the $\mathrm{L}$ and $\mathrm{H}$ profiles together according to the predicted future use of power within the network.

\section{B. Dynamic response control}

The dynamic response of the ESS can be used to impose a limit on the rate-of-change of source power, which is determined by the following procedure.

The steady-state energy profile in Section III.A determines a target energy $E_{t}=f_{s s}\left(P_{L}\right)$ for a given load power $P_{L}$. Therefore, the energy which may be used in response to a load change is the current available energy, E, minus the target energy, $\mathrm{E}_{\mathrm{t}}=\mathrm{f}_{\mathrm{ss}}\left(\mathrm{P}_{\mathrm{L}}\right)$ :

$$
\Delta E=E-E_{t}=E-f_{s s}\left(P_{L}\right)
$$

where $f_{s s}\left(P_{L}\right)$ is either (15), (16) or (17), although other profiles may be used.

The power difference between the load power $\mathrm{P}_{\mathrm{L}}$ and the power source output $\mathrm{P}_{\mathrm{S}}$ is given by:

$$
\Delta P_{L}=P_{L}-P_{S}=P_{E S S}
$$

By substituting (18) and (19) into (4), the rate-of-change of source power is therefore:

$$
k_{c}=\frac{P_{E S S}^{2}}{2\left(E-f_{s s}\left(P_{L}\right)\right)}
$$

which gives the most gradual, constant, rate-of-change in the power source output for a specific load step.

For the purposes of a practical implementation, (20) would be utilized in a real-time controller, where a rate-limit function set by $\mathrm{k}_{\mathrm{c}}$ is constantly updated, and this process is illustrated in Fig. 5. The bracketed term in the denominator of (20) determines the useable energy, given by the difference between the current and target energy; whereas the term in numerator $\mathrm{P}_{\mathrm{ESS}}$ is the difference between source and load powers.

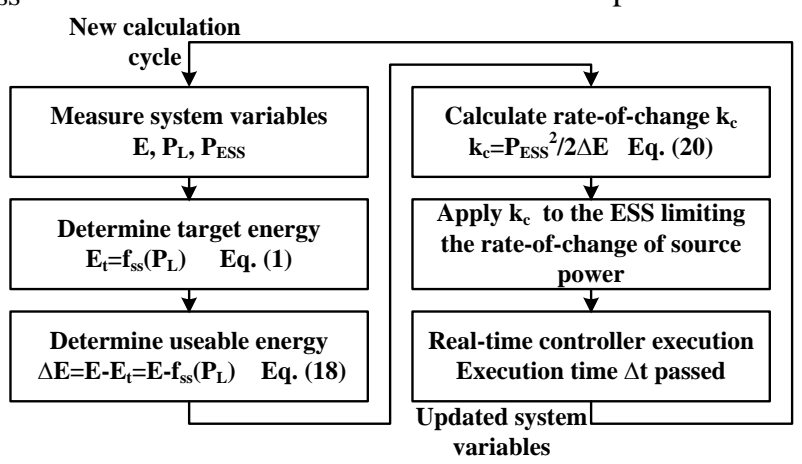

Fig. 5 Flow chart of the $\mathrm{k}_{\mathrm{c}}$ calculation, (20).

\section{GENERIC ESS SIMULATION}

The mathematical equations derived in Section III were used to form a generic ESS simulation model to investigate the ESS and system behaviour. This model is based on the electrical system shown in Fig. 3, which omits the main power source controller dynamics and the ESS inner control dynamics. However the core behaviour of the ESS is preserved, enabling the proposed ESS control method to be assessed without the influence of other system dynamics. The performance of three steady-state energy profiles L, C, H, as described in Section III.A, is examined by simulation using the dynamic response profile described in Section III.B.

\section{A. Model}

An ideal ESS can be modelled assuming that the power flow to/from the storage device, $\mathrm{P}_{\mathrm{ESS}}$, and a differential equation to describe the ESS behaviour can be written by combining (2), (7) and (8):

$$
\dot{E}=P_{E S S}=P_{E S S-r e f}=P_{L}-P_{E S S-r e}=P_{L}-P_{S}
$$

Fig. 6 shows the block diagram of the simplified Simulink model for a generic ESS based on (21). An integrator is used to relate $\mathrm{P}_{\mathrm{ESS}}$ and $\mathrm{E}$, and the summation block reflects the power balance in the electrical system, $\mathrm{P}_{\mathrm{ESS}}=\mathrm{P}_{\mathrm{L}}-\mathrm{P}_{\mathrm{S}}$. The source power $\mathrm{P}_{\mathrm{S}}$ is effectively controlled by the recharge power signal $\mathrm{P}_{\mathrm{ESS}-\mathrm{re}}$ which is set to be equal to the rate-limited variable load power. 
The rate-limiter actively controls the rate-of-change of $\mathrm{P}_{\mathrm{ESS}-\mathrm{re}}$ to $\mathrm{k}_{\mathrm{c}}$ from (20) and so effectively limits the rate-of-change of the source power $\mathrm{P}_{\mathrm{S}}$. Determining $\mathrm{k}_{\mathrm{c}}$ requires the measurement of several system variables including $\mathrm{P}_{\mathrm{L}}, \mathrm{P}_{\mathrm{ESS}}$ and $\mathrm{E}$.

For simplicity, the model uses the per unit system, and is therefore generic. In addition to the base values defined in Section III.A $\left(\mathrm{E}_{\text {base }}=\mathrm{E}_{\max }-\mathrm{E}_{\min }, \mathrm{P}_{\mathrm{L} \text {-base }}=\mathrm{P}_{\mathrm{L} \text {-max }}-\mathrm{P}_{\mathrm{L} \text {-min }}\right)$, the $\mathrm{dP}_{\mathrm{S}} / \mathrm{dt}$ base $\mathrm{k}_{\mathrm{c} \text {-base }}$ and the time base $\mathrm{T}_{\text {base }}$ are defined as:

$$
\begin{gathered}
k_{c-\text { base }}=\frac{P_{L-\text { base }}{ }^{2}}{E_{\text {base }}} \\
T_{\text {base }}=\frac{E_{\text {base }}}{P_{L-\text { base }}}
\end{gathered}
$$

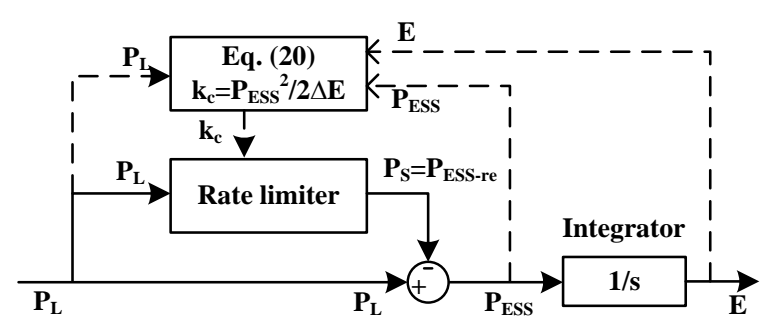

Fig. $6 \mathrm{P}_{\text {ESS-re }}$ control using rate-limiter, (20), for ideal ESS model.

The maximum rate-of-change of source power in per unit $\mathrm{k}_{\mathrm{c}-\max -\mathrm{pu}}$ is therefore:

$k_{c-\max -p u}=\frac{k_{c-\max }}{k_{c-\text { base }}}=\frac{\left(P_{L-\max }-P_{L-\min }\right)^{2}}{2\left(E_{\max }-E_{\min }\right)} / \frac{P_{L-\text { base }}{ }^{2}}{E_{\text {base }}}=0.5$ p.u.

and is the rate that would occur in response to a load step from minimum to maximum.

\section{B. System Design}

Three energy profiles are examined, namely, L, C and H, as previously described in Section III.A. Fig. 7 illustrates these three profiles in per unit form based on (15), (16) and (17) respectively, and the optimal rate-of-change in power $\mathrm{k}_{\mathrm{c}}$ can be calculated using (4) for any load transition from $\mathrm{P}_{\mathrm{L} 1}$ and $\mathrm{P}_{\mathrm{L} 2}$ $\left(\Delta \mathrm{P}=\mathrm{P}_{\mathrm{L} 2}-\mathrm{P}_{\mathrm{L} 1}\right)$ since the useable energy is known to be $\Delta \mathrm{E}=\mathrm{f}_{\mathrm{ss}}\left(\mathrm{P}_{\mathrm{L} 1}\right)-\mathrm{f}_{\mathrm{ss}}\left(\mathrm{P}_{\mathrm{L} 2}\right)$.

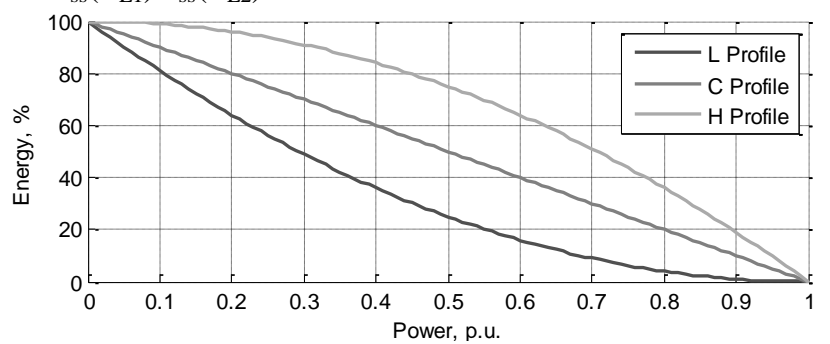

Fig. 7 Three control profiles, L, C and H, for ideal ESS model.

Fig. 8 shows the calculated $k_{c}$ per unit values for different $P_{L 1}$ and $\mathrm{P}_{\mathrm{L} 2}$ combinations using profiles $\mathrm{L}$ and $\mathrm{H}$. For example, a load transition from $\mathrm{P}_{\mathrm{L} 1}=0.2 \mathrm{p}$.u. to $\mathrm{P}_{\mathrm{L} 2}=0.3$ p.u. using profile $\mathrm{L}$ will give $k_{c}=0.03$ p.u. as read from the $P_{L 2}=0.3 p$.u. profile in Fig. 8a. A negative $\mathrm{k}_{\mathrm{c}}$ indicates a load decrease, that is, when $\mathrm{P}_{\mathrm{L} 1}>\mathrm{P}_{\mathrm{L} 2}$.

In Fig. 8, the shaded areas are when both $\mathrm{P}_{\mathrm{L} 1}$ and $\mathrm{P}_{\mathrm{L} 2}$ are less than 0.5 p.u., representing the low load region. In Fig. $8 \mathrm{a}$ where profile $\mathrm{L}$ is used, the low load area is compressed towards the zero line, indicating the $\mathrm{dP}_{\mathrm{S}} / \mathrm{dt}$ rate $\mathrm{k}_{\mathrm{c}}$ is reduced and confirming that the ESS will respond more strongly in the low load region as predicted in Section II.A. However, this sacrifices the performance at high loads, as the $\mathrm{P}_{\mathrm{L} 2}$ curves above $0.5 \mathrm{p}$.u. in Fig. 8a indicate much larger values of $\mathrm{k}_{\mathrm{c}}$, but less than the maximum of $0.5 \mathrm{p}$.u. The situation is reversed when profile $\mathrm{H}$ is used, with the storage system responding more strongly at higher loads, Fig. 8b. For profile $\mathrm{C}$, the rate-of-change in power changes linearly with the load step magnitude, having a maximum rate of $0.5 p . u$. for a 1 p.u. load step.

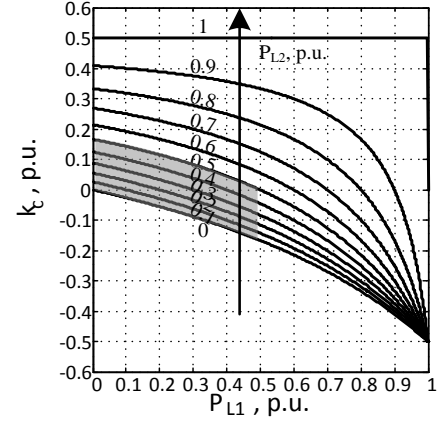

(a) Profile L.

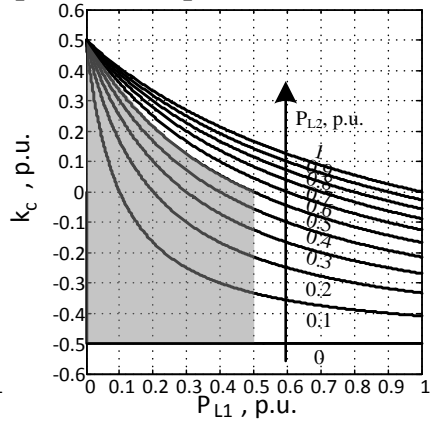

(b) Profile H.
Fig. $8 \mathrm{k}_{\mathrm{c}}$ values calculated for transition from $\mathrm{P}_{\mathrm{L} 1}$ to $\mathrm{P}_{\mathrm{L} 2}$.

The profiles in Fig. 8 show that the maximum rate-of-change in source power $\mathrm{k}_{\mathrm{c}}$ is always lower than $\mathrm{k}_{\mathrm{c}-\mathrm{max} \text {-pu }}=0.5 \mathrm{p}$.u. as calculated in the design stage in Section IV.A.

\section{Results}

A selection of different load profiles, including small and large power changes with different rise/fall rates, have been examined, and sample results are presented and discussed in this section for small load power increases to demonstrate the system operation with the power rate-limited control presented in Section III. The simulation model used is the ideal ESS structure given in Fig. 6, and all three control profiles, shown in Fig. 7, have been implemented to examine the ESS performance. A time base of $\mathrm{T}_{\text {base }}=1 \mathrm{~s}$ is assumed, so that the time in the results is expressed in seconds.

Fig. 9 shows the power source and ESS response for small load steps over the full power range of the load. The load power increases from no-load to 1p.u. in 0.1p.u. steps occurring every $5 \mathrm{~s}$; each step has a $1 \mathrm{~ms}$ rise time.

The load power and source power $\mathrm{P}_{\mathrm{S}}$ are shown in the top plot in Fig. 9; the ESS power is not shown in the plot for clarity, but is the difference between the load and source power. The middle plot in Fig. 9 is the rate-of-change in source power $\mathrm{dP}_{\mathrm{S}} / \mathrm{dt}$ and the bottom plot is the ESS energy E.

For each small load step, the source power in Fig. 9 does not respond instantaneously but has a gradual increase/decrease until it is equal to the load power. During each load transition, the three control profiles cause different system performance which is determined by the energy used. For the load step from 0.2 p.u. to 0.3 p.u. ( $\mathrm{t}=10-15 \mathrm{~s}$ ), profile $\mathrm{L}$, offers the most gradual power source change $\mathrm{dP}_{\mathrm{S}} / \mathrm{dt}=0.03$ p.u., whereas the $\mathrm{dP}_{\mathrm{S}} / \mathrm{dt}$ for profile $\mathrm{C}$ and $\mathrm{H}$ are higher at 0.05 p.u. and 0.1 p.u. respectively; all values match the predicted value from Fig. 8. The energy usage for profile $\mathrm{L}$ is more during this load transition at $15 \%$, compared with $10 \%$ for profile $\mathrm{C}$ and $5 \%$ for profile $\mathrm{H}$, which results in the lowest steady-state energy of $64 \%$.

When the initial load value is $0.5 \mathrm{p} . \mathrm{u}$. $(\mathrm{t}=25 \mathrm{~s})$, the energy usage of the three profiles is similar at approximately $10 \%$ 
giving a $\mathrm{dP}_{\mathrm{S}} / \mathrm{dt}$ value of near 0.05p.u as shown in Fig. 9. During the load transition from 0.7 p.u. to 0.8 p.u., the profile $\mathrm{H}$ results in the lowest $\mathrm{dP}_{\mathrm{S}} / \mathrm{dt}$ since more energy is available for use, and the profile $\mathrm{H}$ is designed to use more energy in this load region.
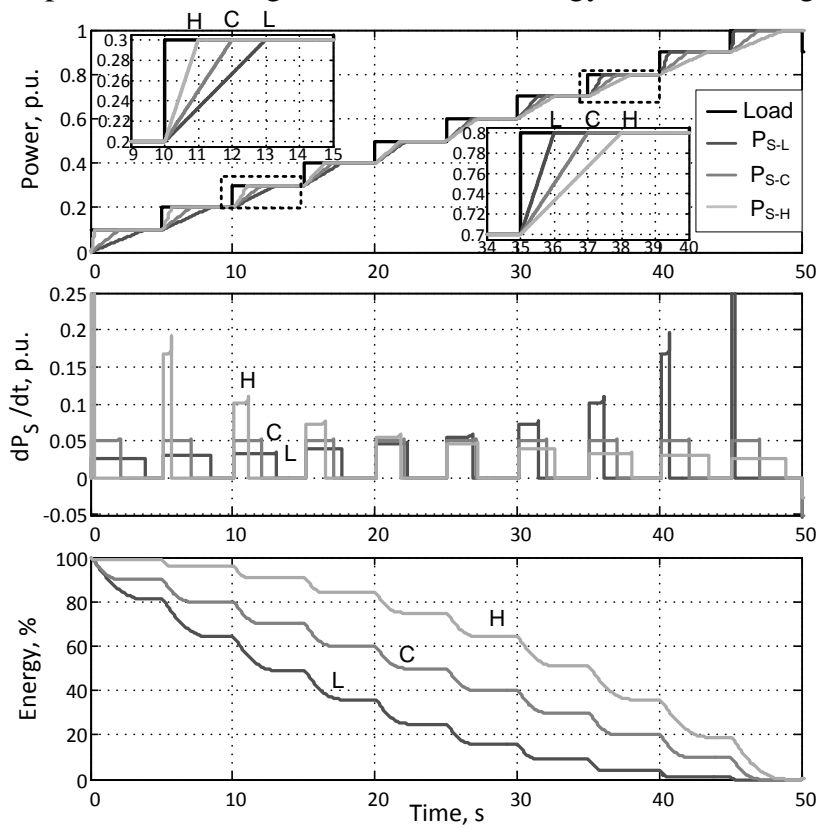

Fig. 9 Small load steps responses.

From zero to full power, the $\mathrm{dP}_{\mathrm{S}} / \mathrm{dt}$ using profile $\mathrm{L}$ increases as the initial values of the 0.1 p.u. load steps increase, illustrated in Fig. 9, second row, where the $\mathrm{dP}_{\mathrm{S}} / \mathrm{dt}$ gradually increases from 0.026p.u. at low load to 0.5p.u. at high load (cropped in Fig. 9), validating the low load oriented design. Profile $\mathrm{H}$ exhibits the opposite effect since it tends to use the stored energy more strongly at heavier load levels, while the $\mathrm{dP}_{\mathrm{S}} / \mathrm{dt}$ for profile $\mathrm{C}$ is constant at 0.05 p.u. for a 0.1 p.u. step with a constant $10 \%$ energy consumption across the full load range.

The steady-state energy values in Fig. 9 match the design data in Fig. 7 for a specific load $P_{L}$, satisfying both $E=f_{s s}\left(P_{L}\right)$ and also $E=f_{s s}\left(P_{S}\right)$ since $P_{S}=P_{L}$ in the steady-state. However, Fig. 10 demonstrates that when the ESS discharges, the energy $\mathrm{E}$ against power source output $\mathrm{P}_{\mathrm{S}}$ trajectory deviates from the ideal control profile, $\mathrm{E} \neq \mathrm{f}_{\mathrm{ss}}\left(\mathrm{P}_{\mathrm{S}}\right)$ during a load transition. The energy against power trajectory from one steady-state condition to another is actually a parabola of the form of (15) (discharge) or (16) (charge). If the profile is closely tracked then $\mathrm{k}_{\mathrm{c}}$ would vary during the load transition and so the constant rate $\mathrm{k}_{\mathrm{c}}$ condition would not be met. This has been confirmed by simulation, however the results are not included here.

A LPF based rate-limit control with a 1s time constant to enable all of the available ESS energy to be used in the event of a full load transition, to match the general characteristic of the profiles in Fig. 10, has also been tested by simulation. The $\mathrm{dP}_{\mathrm{S}} / \mathrm{dt}$ and ESS energy usage depends only on the magnitude of the load step, and not the actual load on the DC bus. The power source output has a first order response, with an initial high $\mathrm{dP}_{\mathrm{S}} / \mathrm{dt}$ which rapidly reduces, and becomes equal to the load power after approximately five time constants; in general the initial $\mathrm{dP}_{S} / \mathrm{dt}$ and settling time are higher from the LPF method than can be achieved by the appropriate profile from Fig. 10, imposing more onerous conditions on the power source.

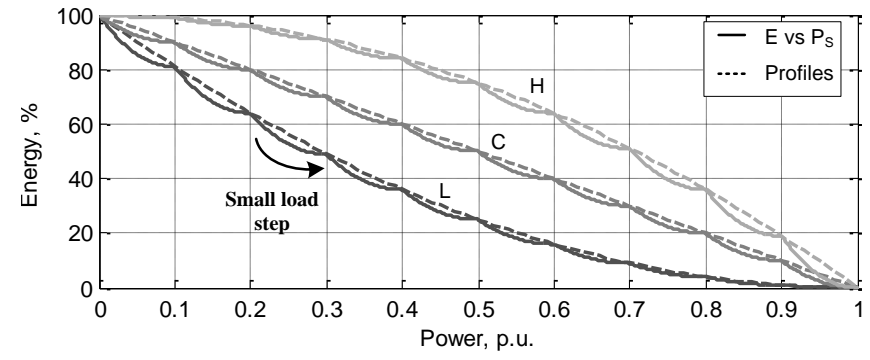

Fig. 10 Energy $E$ against power source output $P_{S}$ trajectories.

\section{EXPERIMENTAL SYSTEM AND VALIDATION}

The energy management control has been implemented on a real 1.14MJ ESS located in an aircraft electrical systems laboratory to demonstrate the practical implementation of the control.

Fig. 11 shows a subset of the aircraft electrical system demonstrator facility, which contains a switched reluctance starter/generator (SRSG) [17], an active load (AL), an energy storage system (ESS), and a background resistive load. The high-speed SRSG operates as the main power source and regulates the DC bus to be nominally $540 \mathrm{~V}$. The active load is used to emulate the dynamic electrical load profiles used in the test program, and a $120 \Omega$ resistive load provides a fixed background load level. The active load current $\mathrm{I}_{\mathrm{AL}}$ is measured in real-time and used as part of the ESS reference $P_{\text {ESS-L }}$ as described in Section III; the background load current is not sensed by the ESS.

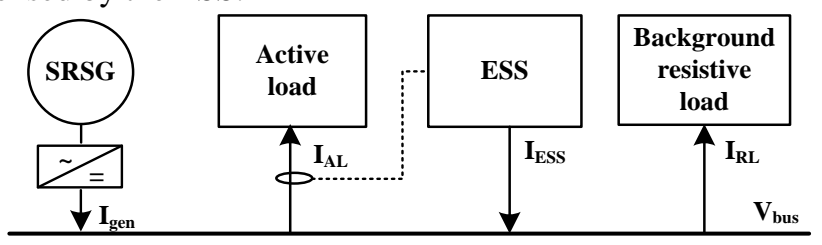

Fig. 11 System diagram.

The ESS consists of three main components, which are the super-capacitor bank which serves as the storage medium, the bi-directional dual interleaved DC-DC converter [18] which interfaces the super-capacitors with the DC bus, and the dSPACE real-time platform (RTP) which is in charge of the overall system. An overall schematic of the ESS is shown in Fig. 12 to show the integration of the main components.

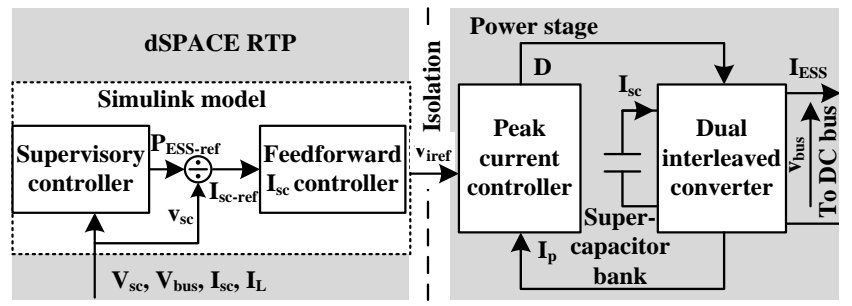

Fig. 12 ESS dSPACE RTP and its connection to the power hardware.

The dSPACE RTP is programmed using a Simulink model, and implements the supervisory power and state-of-charge (SoC) control. The supervisory control determines the super-capacitor current reference $\mathrm{I}_{\text {sc-ref }}$ depending on the load level and SoC, which is calculated by dividing ESS power reference $P_{\mathrm{ESS}}$ in Fig. 6 by super-capacitor voltage, based on the 
method described in Section III. However, the converter cannot be directly commanded using $I_{\text {sc-ref }}$ as the peak current controller (which is part of the converter design [18]) requires a scaled voltage equivalent to $I_{\text {sc-ref }}$, labelled as $v_{\text {iref }}$ in Fig. 12. The mapping of super-capacitor current $I_{\text {sc-ref }}$ to the scaled control reference $v_{\text {iref }}$ is implemented using an inverse-model-based feed-forward current controller [19], which requires accurate modelling of the peak current controller and the DC-DC converter.

The dual-interleaved half-bridge converter used in the experimental system has a $170 \mathrm{~A}$ current limit on the low voltage (super-capacitor) side and can operate up to this maximum current between $180 \mathrm{~V}$ to $288 \mathrm{~V}$ on the low voltage side for $30 \mathrm{~kW}$ operation. Lower voltages are permitted, however with reduced power capability.

The super-capacitor bank used in the experimental system comprises six 48V 165F super-capacitor modules connected in series (BMOD0165, Maxwell), providing a maximum energy of $1.14 \mathrm{MJ}$ and a total voltage of $288 \mathrm{~V}$.

\section{A. Supervisory control design}

The experimental testing involves a sub-set shown in Fig. 11, of the full aircraft demonstrator and so the average load power is low and only a small portion of the system capacity. It is therefore appropriate to undertake experimental tests with the ESS using only profile L. The steady-state SoC target super-capacitor voltage $\mathrm{V}_{\text {sc-t }}$ can be calculated as (25) for profile L, deduced from (11).

$$
V_{s c-t}=\sqrt{\left(V_{s c-\text { max }}^{2}-V_{s c-\text { min }}^{2}\right) \cdot\left(1-P_{L} / P_{L-\max }\right)^{2}+V_{s c-\text { min }}^{2}}
$$

For the convenience of testing the maximum super-capacitor voltage $\mathrm{V}_{\text {sc-max }}$ in the experimental system is set at $250 \mathrm{~V}$ as opposed to the absolute maximum of $288 \mathrm{~V}$. The minimum super-capacitor voltage $\mathrm{V}_{\text {sc-min }}$ is set at $140 \mathrm{~V}$ and so the useable energy is $0.59 \mathrm{MJ}$. The maximum load power $\mathrm{P}_{\mathrm{L}-\max }$ is set to $30 \mathrm{~kW}$, however, for the dual-interleaved converter used in the test system full power operation at the minimum super-capacitor voltage will result in the super-capacitor current slightly exceeding the converter continuous current rating; in these demonstration results the load power is therefore limited to $23 \mathrm{~kW}$.

The maximum rate-of-change in source power $\mathrm{k}_{\mathrm{c}-\max }$ can be calculated using (5) with $\mathrm{P}_{\mathrm{L}-\min }=0$ to give (26):

$$
k_{c-\max }=\frac{P_{L-\max }^{2}}{C_{s c}\left(V_{s c-\max }^{2}-V_{s c-\min }^{2}\right)}
$$

where $\mathrm{C}_{\mathrm{sc}}$ is the super-capacitor bank capacitance, $165 \mathrm{~F} / 6=27.5 \mathrm{~F}$.

The optimal rate-of-change in power for a specific load variation can be calculated using (20) to give:

$$
k_{c}=\frac{P_{E S S}^{2}}{C_{s c}\left(V_{s c}^{2}-V_{s c-t}^{2}\right)}
$$

where $\mathrm{V}_{\text {sc-t }}$ is given by (25).

With the steady-state profile $\mathrm{L}$ given by (25) the variable rate-of-change in power $\mathrm{k}_{\mathrm{c}}$ can be determined from (27), and for a full load transition gives $\mathrm{k}_{\mathrm{c}-\max }=762 \mathrm{~W} / \mathrm{s}$.

\section{B. Experimental Validation}

A hypothetical radar load profile was programmed in the active load to demonstrate the system level performance of the
ESS. The SRSG regulates the DC bus and its voltage droop control is active. The control from Section V.A is used in the ESS with profile L implemented.

Fig. 13 shows simulation and test results for the ESS and generator when the radar load paralleled with a $120 \Omega$ resistive load is applied. The radar profile contains four power steps which are $4 \mathrm{~kW}, 5 \mathrm{~kW}, 21 \mathrm{~kW}$ and $7 \mathrm{~kW}$ at times $\mathrm{t}=5 \mathrm{~s}, 30 \mathrm{~s}, 50 \mathrm{~s}$ and 100 s.

The simulation results are obtained from a model using a first order RC network super-capacitor representation [20] and the averaged DC-DC converter model with the simple low level super-capacitor current control from [21], the supervisory ESS control of Section V.A, and a behavioural model of the SRSG [17]. The detailed ESS simulation behaviour will differ from the experimental ESS, however the effect of the different converter and low level control will be negligible on the system level behaviour as it is the supervisory control which determines the system level operation.

The results in Fig. 13 show two consecutive radar load cycles; the first plot is the active load (AL) and ESS currents $\mathrm{I}_{\mathrm{AL}}$ and $\mathrm{I}_{\mathrm{ESS}}$, the second plot is the generator current $\mathrm{I}_{\mathrm{gen}}$, the third and fourth plots are the super-capacitor current $\mathrm{I}_{\mathrm{sc}}$ and voltage $\mathrm{V}_{\mathrm{sc}}$, respectively and the last plot is the bus voltage $\mathrm{V}_{\text {bus }}$. The super-capacitor current reference $\mathrm{I}_{\text {sc-ref, }}$ produced by the supervisory controller is also plotted, shown in green in the third plot (recorded by dSPACE RTP). The experimental data and simulation results are overlaid to demonstrate the close match between the data sets. The instantaneous efficiency of the experimental ESS at $\mathrm{t}=30 \mathrm{~s}$ and $\mathrm{t}=50 \mathrm{~s}$ are $95.8 \%$ and $96.3 \%$ respectively, and $89.9 \%$ at $\mathrm{t}=95 \mathrm{~s}$ in light charging mode.

The generator current response exhibits different constant rates-of-change in current following each load transient in Fig. 13. The state-of-charge control determines the specific rate-of-change in generator power for each load according to the available ESS energy. This is most visible in Fig. 13 during the high power step when the $\mathrm{dP}_{\mathrm{S}} / \mathrm{dt}$ from the experimental results is $385 \mathrm{~W} / \mathrm{s}$ which is in good agreement with the simulation value of $331 \mathrm{~W} / \mathrm{s}$ and $337 \mathrm{~W} / \mathrm{s}$ from theoretical calculation. At the $7 \mathrm{~kW}$ load point the $\mathrm{dP}_{\mathrm{S}} / \mathrm{dt}$ from the experimental results is $-90 \mathrm{~W} / \mathrm{s}$, which again is in good agreement with the simulation value of $-89 \mathrm{~W} / \mathrm{s}$ and $-83 \mathrm{~W} / \mathrm{s}$ from theoretical calculation.

The low rate-of-change in generator power imposed by the supervisory ESS control results in the ESS never reaching a steady-state value in Fig. 13, though the ESS output is approaching zero for all load powers. For example, considering the peak power of $21 \mathrm{~kW}$ from $30 \mathrm{~s}$ to $50 \mathrm{~s}$, the super-capacitor voltage should be $153 \mathrm{~V}$ in the steady-state, (25) however the measured voltage is $163 \mathrm{~V}$ at 50 s in Fig. 13; if the load does not change at $50 \mathrm{~s}$ then the super-capacitor would continue discharging until the voltage settles around the target of $153 \mathrm{~V}$.

In Fig. 13 there are two noticeable voltage transients per load cycle, with magnified plots being shown in the boxes in Fig. 13, which are caused by the sudden decrease in ESS current. At $t=23.7 \mathrm{~s}$, the super-capacitor current reference $I_{\text {sc-ref }}$ (third row, green) reaches the ESS dead-band threshold of $\pm 2 \mathrm{~A}$, during which the ESS is disabled to avoid sudden changes in power flow direction; however, the actual super-capacitor current is $-10 \mathrm{~A}$ and the ESS output current is -4A (charging), with the error in reference and actual $\mathrm{I}_{\mathrm{sc}}$ being caused by the inaccuracy 
of the feed-forward super-capacitor current control. Disabling the ESS when the output is $-4 \mathrm{~A}$ and not zero causes a step load decrease on the generator, which increases the bus voltage, triggering the resetting of the integral component in the generator voltage control [17]. In addition, the bus voltage transient at $\mathrm{t}=94.5 \mathrm{~s}$ interacts with ESS controller which causes a small pulse in $\mathrm{I}_{\mathrm{sc}-\mathrm{ref}}$ at $\mathrm{t}=95 \mathrm{~s}$.
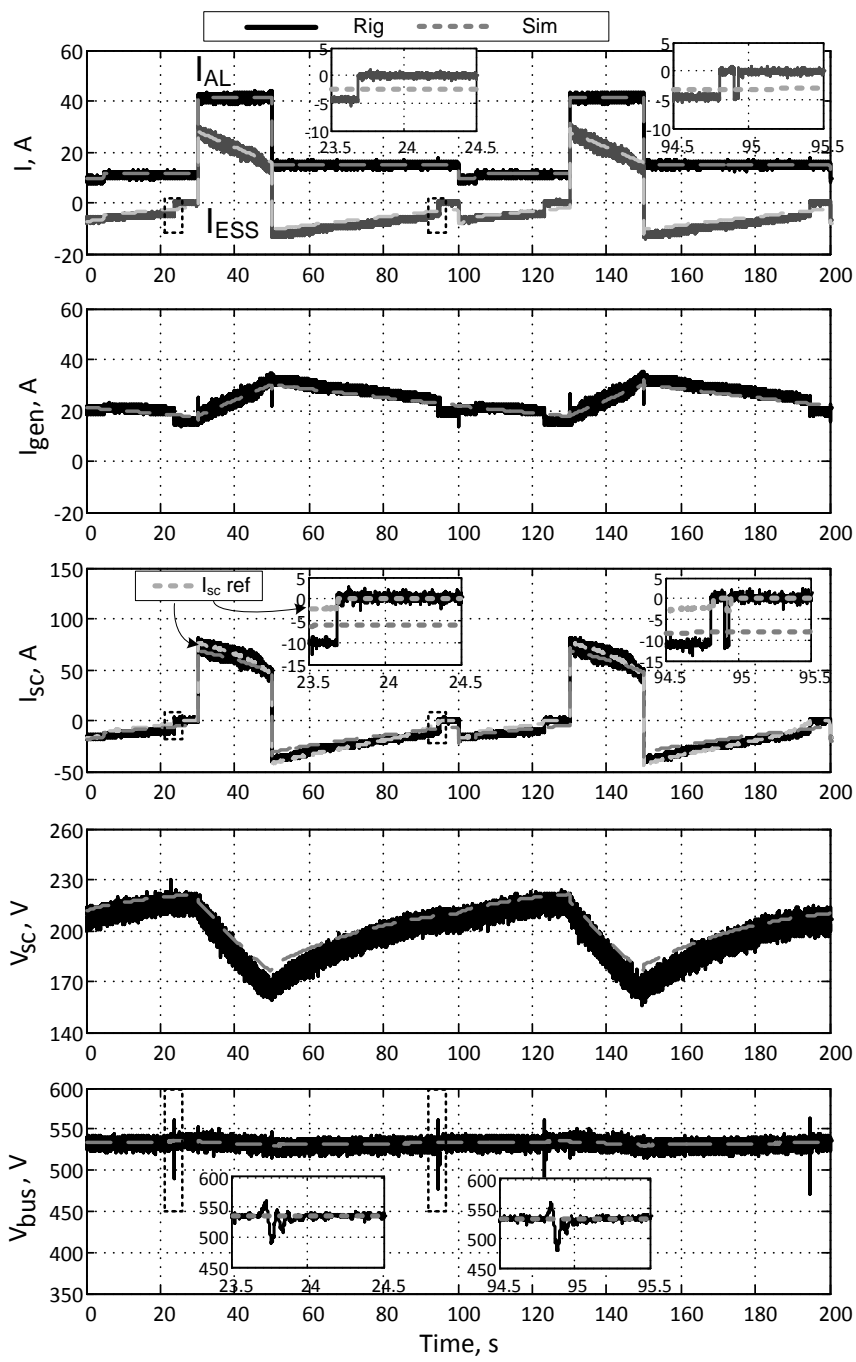

Fig. 13 Overall system response due to hypothetical radar load.

In general, the results from the simulation correlate well with the test data, with the exception of the transients resulting from the deactivation of the ESS, and that the super-capacitor voltage in the simulation is always higher than the experimental value. A number of issues may contribute to the difference in super-capacitor voltage, including converter efficiency, feed-forward control inaccuracy and measurement errors, and it is not completely clear which effect is most significant in determining the ESS behaviour. The effect of converter losses are apparent during the high power period from 30s to 50s, where the super-capacitor current from the experiment is higher than the simulation result, causing deeper super-capacitor discharge, while achieving the same ESS current.

\section{CONCLUSION}

A supervisory energy management control with an adaptive rate-limit function is proposed for an ESS. The objective of the control is to protect the primary power source from sudden load transients within the constraints of the available stored energy. This strategy is likely to allow the power source to operate under more favourable, slowly varying conditions, minimizing the potentially life-time limiting effects of rapid transients. Furthermore, the efficiency of a primary power source, such as a jet engine, is likely to be higher if its operating point changes gradually. The control enables the ESS to be used more aggressively within specific load ranges, whilst reserving sufficient energy to limit future power source transients to a maximum level.

The performance of the adaptive energy management control has been demonstrated using a generic ESS simulation and a real super-capacitor based ESS in an aircraft electrical system demonstrator. The generic ESS simulation results perfectly match the theoretical prediction in terms of energy usage and rate-of-change in power source output, validating the control concept for all three energy profiles. The proposed control using profile $\mathrm{L}$ was implemented on a super-capacitor ESS and the system response to a hypothetical radar load shows ESS energy usage in accordance with the energy profile and well controlled rates-of-change in the generator power.

More generally this work demonstrates the importance of energy storage in aircraft power networks for a range of functions including limiting the rate-of-change in demanded power source output, managing the ESS energy usage and system stability. Optimising these multiple objectives and examining the performance of the ESS in more complex power networks are topics for further research.

\section{ACKNOWLEDGMENT}

The authors would like to thank Rolls-Royce plc for the financial support of this work through the University Technology Centre in Power Conversion Systems at The University of Manchester. The authors are also grateful to Dr. Gerardo Calderon-Lopez for the bi-directional DC-DC converter used in the hardware system. Author Ding Wu thanks EPSRC for financial support through the Dorothy Hodgkin Postgraduate Award scheme.

\section{REFERENCES}

[1] X. Roboam, B. Serani A.D. Andrade, "More Electricity in the Air: Toward Optimized Electrical Networks Embedded in More-Electrical Aircraft," IEEE Industrial Electronics Magazine, vol.6, no.4, pp. 6-17, 2012.

[2] A. Emadi, A. Khaligh, C.H, Rivetta and G.A. Williamson, "Constant Power Loads and Negative Impedance Instability in Automotive Systems: Definition, Modeling, Stability, and Control of Power Electronic Converters and Motor Drives," IEEE Trans. Veh. Technol., vol.55, no.4, pp.1112-1125, 2006.

[3] J. Moreno, M.E. Ortuzar and J.W. Dixon, "Energy-Management System for a Hybrid Electric Vehicle, using Ultracapacitors and Neural Networks," IEEE Trans. Ind. Electron., vol. 53, pp. 614-623, 2006.

[4] J. Dixon, I. Nakashima, E. F. Arcos and M. Ortuzar, "Electric Vehicle using a Combination of Ultracapacitors and ZEBRA Battery," IEEE Trans. Ind. Electron., vol. 57, pp. 943-949, 2010.

[5] D. Iannuzzi and P. Tricoli, "Speed-Based State-of-Charge Tracking Control for Metro Trains with Onboard Supercapacitors," IEEE Trans. Power Electron., vol. 27, pp. 2129-2140, 2012.

[6] G. Xu, L. Xu, D.J. Morrow and D. Chen, "Coordinated DC Voltage Control of Wind Turbine with Embedded Energy Storage System," IEEE Trans. Energy Convers., vol. 27, no. 4, pp. 1036-1045, 2012. 
[7] P. Thounthong, S. Rael and B. Davat, "Control Strategy of Fuel Cell and Supercapacitors Association for a Distributed Generation System," IEEE Trans. Ind. Electron., vol. 54, pp. 3225-3233, 2007.

[8] Y. Zhang, H. Liu and Q. Guo, "Varying-Domain Optimal Management Strategy for Parallel Hybrid Electric Vehicles," IEEE Trans. Veh. Technol., vol. 63, no. 2, pp. 603-616, 2014.

[9] H. Zhang, F. Mollet, C. Saudemont and B. Robyns, "Experimental Validation of Energy Storage System Management Strategies for a Local DC Distribution System of More Electric Aircraft," IEEE Trans. Ind. Electron., vol. 57, no.12, pp.3905-3916, 2010.

[10] N. Mendis, K.M. Muttaqi and S. Perera, "Management of Low- and High-Frequency Power Components in Demand-Generation Fluctuations of a DFIG-Based Wind-Dominated RAPS System Using Hybrid Energy Storage," IEEE Trans. Ind. Appl., vol. 50, pp. 2258-2268, 2014.

[11] C. Abbey, L. Wei and G. Joos, " An Online Control Algorithm for Application of a Hybrid ESS to a Wind-Diesel System," IEEE Trans. Ind. Electron., vol.57, no.12, pp.3896-3904, 2010.

[12] F.S. Garcia, A.A. Ferreira and J.A. Pomilio, "Control Strategy for Battery-Ultracapacitor Hybrid Energy Storage System," IEEE Applied Power Electronics Conference and Exposition, pp. 826-832, 2009.

[13] Y. Cheng, J. Van Mierlo, P. Lataire, M. Lieb, E. Verhaeven and R. Knorr, "Configuration and Verification of the Super Capacitor Based Energy Storage as Peak Power Unit in Hybrid Electric Vehicles," European Conference on Power Electronics and Applications, pp. 1-8, 2007.

[14] J.M.A. Curti, X. Huang, R. Minaki and Y. Hori, "A Simplified Power Management Strategy for a Supercapacitor/Battery Hybrid Energy Storage System using the Half-Controlled Converter," IEEE Industrial Electronics Society (IECON), pp. 4006-4011, 2012.

[15] L. Battistelli, M. Fantauzzi, D. Iannuzzi and D. Lauria, "Energy Management of Electrified Mass Transit Systems with Energy Storage Devices," International Symposium on Power Electronics, Electrical Drives, Automation and Motion (SPEEDAM), pp. 1172-1177, 2012.

[16] D. Wu, R. Todd and A.J. Forsyth, "Advanced Energy Management Control for Energy Storage System," IET International Conference on Power Electronics, Machines and Drives, 2014.

[17] V. Valdivia, R. Todd, F.J. Bryan, A. Barrado, A. Lazaro and A.J. Forsyth, "Behavioral Modeling of a Switched Reluctance Generator for Aircraft Power Systems," IEEE Trans. Ind. Electron., vol.61, no.6, pp.2690-2699, 2014.

[18] G. Calderon-Lopez and A.J. Forsyth, "High-Power Dual-Interleaved ZVS Boost Converter with Interphase Transformer for Electric Vehicles," IEEE Applied Power Electronics Conference and Exposition (APEC), pp. 1078-1083, 2009.

[19] S. Devasia, "Should Model-Based Inverse Inputs be used as Feedforward Under Plant Uncertainty?," IEEE Trans. Autom. Control, vol. 47, pp. 1865-1871, 2002.

[20] R.L. Spyker, R.M. Nelms and S.L. Merryman, "Evaluation of Double Layer Capacitors for Power Electronic Applications," IEEE Applied Power Electronics Conference and Exposition (APEC), 1996.

[21] R. Todd, D. Wu, J.A. dos Santos Girio, M. Poucand and A.J. Forsyth, "Supercapacitor-Based Energy Management for Future Aircraft Systems," Twenty-Fifth Annual IEEE Applied Power Electronics Conference and Exposition (APEC), pp. 1306-1312, 2010.

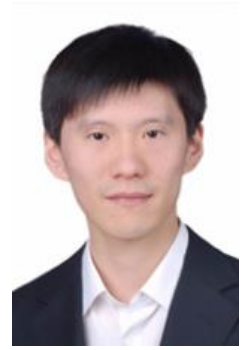

Ding Wu was born in Taizhou, China, 1987. He received his B.Eng. and Ph.D. degrees at the University of Manchester in 2009 and 2013 respectively.

He is currently working as a post-doctoral Research Associate in the Rolls-Royce University Technology Centre at the University of Manchester. His research interests include high power DC-DC converters and energy storage systems using supercapacitors and batteries for aircraft applications.

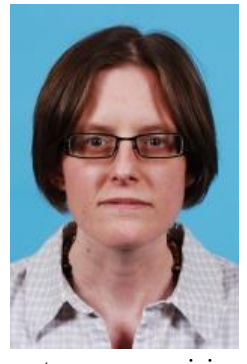

Rebecca Todd (M'08-SM'12) received the M.Eng. degree from the University of Manchester Institute of Science and Technology, Manchester, U.K., in 2001 and the Eng.D. degree from the University of Manchester, Manchester, U.K., in 2006.

She was a Research Associate in the Rolls-Royce University Technology Centre from 2006 to 2010, and since 2010 has been a Lecturer at The University of Manchester. Her research interests include advanced control methods, supercapacitor-based energy storage devices and energy management for on-board electrical systems comprising multiple, engine embedded generators and power electronic motor drive loads.

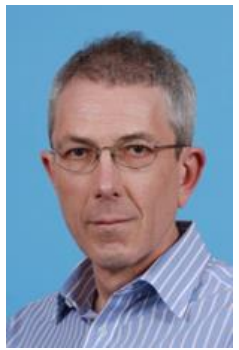

Andrew J. Forsyth (M'98-SM'07) received the B.Sc.(Eng.) degree from Imperial College, London, U.K., in 1981 and the Ph.D. degree from the University of Cambridge, Cambridge, U.K., in 1987.

He was a Design Engineer with GEC Electrical Projects, Ltd., from 1981 to 1983, a Lecturer with the University of Bath from 1986 to 1990 , and a Lecturer/Senior Lecturer with Birmingham University from 1991 to 2004. Since 2004, he has been Professor of Power Electronics with the School of Electrical and Electronic Engineering, The University of Manchester, Manchester, U.K. His research interests include high-frequency converters, high-power-factor rectifiers, modeling and control of autonomous power systems, and aerospace and electric-vehicle applications. 